\title{
Foetomaternal Outcome of Labour with Epidural Analgesia - Prospective, Comparative and Interventional Study
}

\author{
Vaishnavi Sanjay Shivade1, Manisha Manish Laddad² \\ ${ }^{1}$ Department of Obstetrics and Gynaecology, KIMS, Karad, Maharashtra, India. \\ ${ }^{2}$ Department of Obstetrics and Gynaecology, KIMS, Karad, Maharashtra, India.
}

\section{ABSTRACT}

\section{BACKGROUND}

Labour is an extremely painful process. Labour pain can have deleterious effects on the mother, on the foetus and on the labour outcome. Among the current methods of obstetric analgesia, regional analgesia (the most widespread technique being epidural analgesia) offers the best effectiveness/safety ratio. The increased availability of epidural analgesia and the favourable experiences of women who have had painless labour with epidural block have reshaped the expectations of pregnant women entering labour. Compared with other forms of pain relief, epidural analgesia is associated with the highest level of maternal satisfaction. Taking into consideration this aspect, a study was performed in a tertiary care center over a period of 18 months.

\section{METHODS}

160 patients fulfilling the inclusion criteria were divided into two groups namely Group A and Group B. Group A was administered epidural analgesia while Group B was offered other analgesic agents (inj. tramadol hydrochloride) after obtaining well informed consent. Pain compliance is marked over VAS at this point of time. Once the effect of epidural starts waning off, top up dosages are administered by anaesthesiologists. Increments or derangements in pain compliance are noted timely. Any maternal side effects such as headache, hypotension, motor paralysis etc. are noted. Duration of first and second stage of labour is noted with the help of partogram. In the end, mode of delivery, indication of instrumental delivery/caesarean section, neonatal outcome in terms of APGAR scores were noted.

\section{RESULTS}

Prolongation of first and second stage of labour, increase in the rate of instrumental/caesarean delivery was not statistically significant between both the groups. $(p>0.05)$. p Value calculated using unpaired t test $(p=0.5116)$. Maternal requests for caesarean section were significantly higher in control group compared to epidural group $(\mathrm{p}<0.05)$. This may be due to non/less efficacy of other analgesic drugs than epidural analgesics. The difference in VAS score between both the study groups was statistically significant $(\mathrm{p}<0.001)$ indicating that pain was significantly less in epidural group.

\section{CONCLUSIONS}

Epidural analgesia provides excellent labour analgesia compared to other agents with no significant prolongation of first and second stage of labour or mode of delivery. Study also shows that there is no significant rise in the number of instrumental or caesarean deliveries due to epidural analgesia. There are no serious maternal or foetal side effects of the epidural analgesia. Hence, it can be safely recommended in labour. The analgesic effect can be maintained as long as needed and even after delivery to relieve postoperative pain.

\section{KEY WORDS}

Epidural Analgesia, Visual Analogue Scale Score, Labour
Corresponding Author: Dr. Manisha Manish Laddad, Shri Sai Hospital, Malkapur, Post Karad, Dist., Satara-415110, Maharashtra, India.

E-mail:drmanishald@gmail.com

DOI: 10.14260/jemds/2020/212

Financial or Other Competing Interests: None.

How to Cite This Article:

Shivade VS, Laddad MM. Foetomaternal outcome of labour with epidural analgesia- prospective, comparative and interventional study. J. Evolution Med. Dent. Sci. 2020;9(12):985-990, DOI: $10.14260 /$ jemds $/ 2020 / 212$

Submission 21-01-2020,

Peer Review 04-03-2020,

Acceptance 10-03-2020,

Published 23-03-2020.

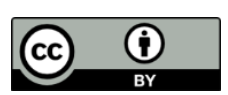




\section{BACKGROUND}

Experiencing labour pains and giving birth to infant is normal physiological process. Though it is a natural phenomenon, it produces severe pain which requires analgesia to relieve pain during labour. ${ }^{1}$ Distension of the birth canal in the first and second stage of labour causes tremendous pressure on the local tissues. ${ }^{2}$ This leads to forceful stretching of facia and subcutaneous tissue. This can also lead to tearing of fascia and tremendous strain on perineal muscles. Visceral afferent nerve fibres which are going with sympathetic nerve fibres transmits pain signals from stretching lower segment of uterus and cervix. These fibres enter the spinal cord at the tenth, eleventh, and twelfth thoracic and first lumbar spine. The pudendal nerves transmit somatic sensory impulses from the vagina and perineum are transmitted via the pudendal nerves to the second, third and fourth sacral spinal segments. $^{3}$ Referred pain to the lower lumbar and sacral portions is mainly due to stimulation of root base of the lumbo-sacral plexus structures. ${ }^{4}$

Complete analgesia for both first and second stages of labour is provided by epidural and intrathecal blockade (neuraxial blockade). An epidural anaesthesia is a procedure used to make a woman more comfortable during labour. The term 'epidural' refers to "the space of spine where local anaesthetic is delivered. It is a local anaesthetic, which freezes a person from the abdomen to the feet. Epidural anaesthesia along with an experienced anaesthetist, a dedicated obstetrician and a trained midwife has ability to convert the painful and extensively stressful labour event into a less stressful event. ${ }^{5}$

Epidural analgesia is associated with prolonged labour, which in turn leads to assisted vaginal birth. ${ }^{6}$ Some factors are associated with no pain relief or block failure with epidural such as, obesity, multiparity, cervical dilation of more than $7 \mathrm{~cm}$ at insertion, history of previous failure of epidural anaesthesia etc. ${ }^{7}$

With this background, the purpose of this study was to compare foetomaternal outcome of labour with epidural analgesia to those without epidural analgesia.

\section{METHODS}

\section{Inclusion Criteria}

- Nullipara.

- Women with age between 20 to 35 year.

- Less than $80 \mathrm{~kg}$ of body weight.

- Gestational age at least 36 wk., and not more than 42 .

- $\quad$ Singleton pregnancy.

- Fetus in vertex position.

- $3 \mathrm{~cm}$ or more cervical dilatation.

- Voluntarily requested for analgesia (study group). Fit with respect to anaesthesia requirement (e.g. Normal coagulation profile, no bleeding disorder or spine abnormality etc.).

- Voluntarily desired not to have epidural analgesia (Control group).

\section{Exclusion Criteria}

- Multipara,
- Age below 20 yrs. or above 35 year,

- Gestation age least than 36 week or more than 42 weeks,

- Cephalopelvic disproportion

- Malpresentation.

- Cervical dilatation $<3 \mathrm{cms}$ and $>6 \mathrm{cms}$

- Medical complications (preeclampsia, eclampsia, diabetes, etc),

- Any contraindications for epidural analgesia (coagulopathy, marked hypovolemia, neurological disorders, allergies to local anaesthetics, etc), and

- Patient's denial or inability to cooperate for epidural analgesia.

\section{Sample Size}

Applying formula-

$\mathrm{n}=\frac{\left(\mathrm{SD}_{1}{ }^{2}+\mathrm{SD}_{2}{ }^{2}\right) \times 13}{\left(\mathrm{X}^{1}-\mathrm{X}^{2}\right)^{2}}$

Where, $\mathrm{n}=$ Sample size

$\mathrm{SD}=$ Standard Deviation

$\mathrm{X}=$ Mean

Considering previous studies,

\section{Group 1: Study Group}

Nulliparous women fulfilling the above criteria and who desired epidural analgesia were allocated in the Group I (epidural group) ( $\mathrm{n}=80$ ),

\section{Group 2: Control Group}

Women who did not desire any labour analgesia were allocated in the Group II (control or non-epidural group) $(n=80)$.

\section{Method of Data Collection}

- After proper selection of case, and obtaining well informed written consent from patient and the relatives, 20 gauge cannula is secured in patient and preloading with $500 \mathrm{ml}$ of Ringer Lactate is done. Pain compliance is marked over VAS before administration. Prophylactic single dose of antibiotic (inj. Taxim $1 \mathrm{gm}$ iv) is given.

- $\quad$ Patient is then shifted to Operation Theatre and is placed in left lateral position. A17 Tuohy needle is inserted into the second or third lumbar interspace with orifice of needle pointing towards the head. Epidural puncture is made using loss of resistance technique.

- A vinyl plastic catheter is inserted through the needle which is removed over catheter. A test dose of 2-3 ml of local anaesthetic agent is given and patient is observed for any signs of systemic hypersensitivity. Rest of the anaesthetic agent (4-6 ml) is then given.

- Patient is then mobilised to labour room. Pain compliance is marked over VAS at this point of time. Pulse, blood pressure, FHS and uterine contractions are monitored every 15 minutes in first 2 hours and every 30 minutes then onwards. Per vaginal examination is done as and when required (mostly every $4^{\text {th }}$ hourly in latent phase and every 3 hourly in active phase of labour).

- Once the effect of epidural starts waning off, top up dosages are administered by anaesthesiologists. 
Increments or derangements in pain compliance are noted timely.

- Any maternal side effects such as headache, hypotension, motor paralysis etc. are noted.

- Augmentation of labour is done if necessary, by using Inj. Pitocin with titrating doses.

- Duration of first and second stage of labour is noted with the help of partogram.

- In the end, mode of delivery, indication of instrumental delivery/caesarean section, neonatal outcome in terms of APGAR scores at 1 minute, 5 minutes and 10 minutes observed.

- Epidural catheter is removed on first postnatal/postoperative day.

- Similarly, in control group, analgesics such as Inj. Tramadol Hydrochloride $(50 \mathrm{mg} / \mathrm{mL})$, INJ. Drotin $(40$ $\mathrm{mg} / \mathrm{mL}$ ) was given timely by intramuscular route and similar findings as above are noted.

\section{Statistical Analysis}

All collected information was entered in to excel sheet and analysed using software Epi Info $^{\mathrm{TM}}$ For Windows version 7.2. All qualitative data were presented by frequency and percentage. All quantitative data were presented by mean and standard deviation. Initially baseline profile were compared between study group and control group. This was followed by comparison of outcome variable between study group and control group. Statistical difference between two groups were assessed using chi square for study variable was qualitative and unpaired $t$ test when study variable was quantitative. $\mathrm{P}$ value less than 0.05 was considered as statistically significant.

\section{Ethical Consideration}

Study was conducted only after approval of institutional ethical committee. All the subjects were explained about the study in the vernacular language. Participation in the study was purely voluntary and all women were informed about their write to withdraw at any stage of the study. An informed written consent was obtained from all participants before the study. Data were analysis and presented without direct identifier of the cases.

\section{RESULTS}

The present study was conducted to compare foetomaternal outcome of labour with epidural analgesia to those without epidural analgesia. In both group 80 cases were recruited in each group. The observations of the study are presented below-

2 There was no statistical difference between the mean age of both the study groups ( $\mathrm{p}>0.05)$. P value calculated using unpaired t test $=0.3063$

3 There was no statistical difference between the mean weight of both the study groups $(p>0.05)$. P value calculated using unpaired t test $=0.6134$

4 There was no statistical difference between the mean height of both the study groups $(p>0.05)$. P value calculated using unpaired t test $=0.5057$
5 The comparison of duration of first stage of labour between Epidural group and control group. Duration of first stage of labour was 6 to 8 hours in $72.5 \%$ women in epidural group and $73.8 \%$ women in control group. Mean duration of first stage of labour in epidural group was 6.76 hours with standard deviation of 1.96 while mean duration of first stage of labour in control group was 7.16 hours with standard deviation of 1.82 . There was no statistical difference between the mean duration of first stage of labour in both the study groups $(p>0.05) . P$ value calculated using unpaired $t$ test $=$ 0.5116

6 The comparison of duration of second stage of labour between Epidural group and control group. Duration of second stage of labour was 30 to $44 \mathrm{~min}$ in $56.3 \%$ women in epidural group and $37.5 \%$ women in control group. Average time of second stage of labour in epidural group was 46.04 minutes with standard deviation of 13.28 while mean duration of second stage of labour in control group was 42.93 min with standard deviation of $12.10 \mathrm{~min}$. There was no statistical difference between the mean duration of second stage of labour in both the study groups $(p>0.05)$. $p$ value calculated using unpaired t test $=0.4357$

7 Caesarean sections were $20.0 \%$ and $15.0 \%$ in epidural group and in control group respectively. There was no statistical difference between the mode of delivery in both the study groups ( $\mathrm{p}>0.05$ )

8 For instrumental delivery, foetal distress was responsible for 4 cases and prolonged second stage was in 8 cases, however there was no statistical difference in indication of instrumental delivery in both the study groups ( $p>0.05)$. Foe caesarean section, foetal distress, prolonged second stage, maternal request and nonprogress in labour were the indication. Maternal requests for caesarean section were significantly higher in control group compared to epidural group $(\mathrm{p}<0.05)$

9 For caesarean section, foetal distress, prolong second stage, maternal request and nonprogress in labour were the indication. Maternal requests for caesarean section were significantly higher in control group compared to epidural group $(\mathrm{p}<0.05)$

10 At 1 min mean APGAR score was less than 7 in 5 (6.3\%) and $4(5 \%)$ babies respectively in epidural group and control group. However, the difference was statistically not significant $(p>0.05)$. At 5 min mean APGAR score was 7 or more in all cases both in epidural group as well as control group.

11 The difference in VAS score between both the study groups was statistically significant $(\mathrm{p}<0.001)$ indicating that pain was significantly less in epidural group

12 During the first stage of labour mean VAS was significantly less in epidural group (1.46) compared to control group (6.84) $(\mathrm{p}<0.001)$. Similarly, during the second stage also the mean VAS was significantly less in epidural group (2.02) compared to control group (8.00) $(\mathrm{p}<0.001)$.

13 When side effects were considered, hypotension \& tachycardia was found in $2(2.5 \%)$, Urinary retention was found in $1(1.3 \%)$, Backache was found in $2(2.5 \%)$, Headache was found in 3 (3.8\%), Pyrexia was found in 2 (2.5\%), and Motor Paresis was found in 1 (1.3\%). 


\begin{tabular}{|ccccc|}
\hline Mode of Delivery & $\begin{array}{c}\text { Epidural Group } \\
\text { (n=80) }\end{array}$ & $\mathbf{\%}$ & $\begin{array}{c}\text { Control Group } \\
\text { (n=80) }\end{array}$ & $\%$ \\
Normal vaginal & 57 & $71.3 \%$ & 63 & $78.8 \%$ \\
Instrumental vaginal & 7 & $8.8 \%$ & 5 & $6.3 \%$ \\
Caesarean section & 16 & $20.0 \%$ & 12 & $15.0 \%$ \\
Total & 80 & $100.0 \%$ & 80 & $100.0 \%$ \\
\hline \multicolumn{4}{c}{ Table 1. Comparison of Mode of Delivery } \\
between Epidural Group and Control Group \\
\hline p value calculated using chi-square test = 0.5475. \\
\hline
\end{tabular}

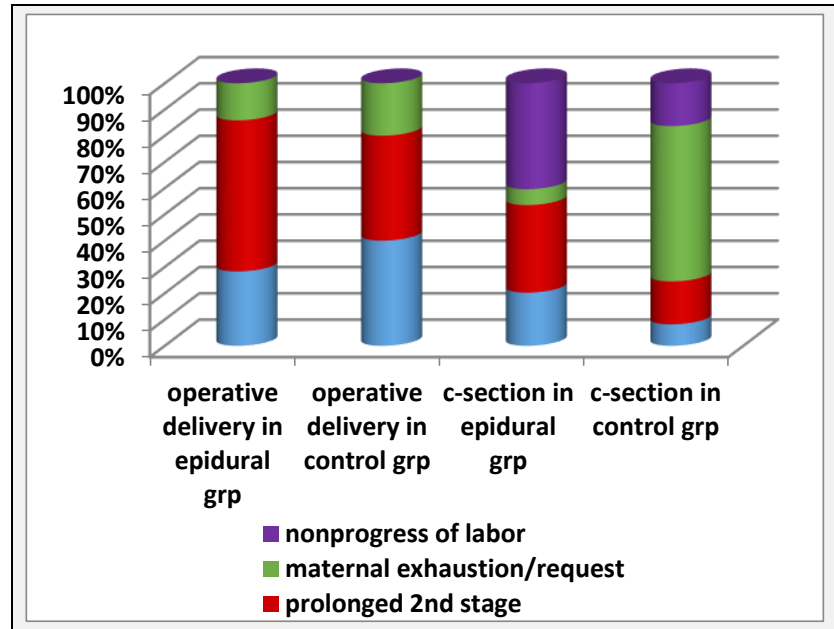

Graph 1. Comparison of Indication of Operative Delivery between Epidural Group and Control Group

$\mathrm{p}$ value was calculated using $\mathrm{Z}$ test of proportion, $\mathrm{P}<0.05$ indicate statistical significance.

\begin{tabular}{|ccccc|}
\hline $\begin{array}{c}\text { Quality of } \\
\text { Analgesia (VAS) }\end{array}$ & $\begin{array}{c}\text { Epidural } \\
\text { Group (n=80) }\end{array}$ & $\begin{array}{c}\text { \%age } \\
\text { Excellent (0-2) }\end{array}$ & $\begin{array}{c}\text { Control } \\
\text { Group (n=80) }\end{array}$ & \%age \\
Good (3-4) & 27 & $43.8 \%$ & 4 & $5.0 \%$ \\
Satisfactory (5-6) & 8 & $33.8 \%$ & 3 & $3.8 \%$ \\
Inadequate (7-8) & 6 & $10.0 \%$ & 10 & $12.5 \%$ \\
Failure (9-10) & 4 & $7.5 \%$ & 50 & $62.5 \%$ \\
Total & $\mathbf{8 0}$ & $\mathbf{1 0 0 . 0 \%}$ & 13 & $16.3 \%$ \\
\hline \multicolumn{5}{c}{ Table 2. Comparison of Quality of Analgesia } \\
between Epidural Group and Control Group \\
\hline p value calculated using chisquare test =< <0.001. \\
\hline
\end{tabular}

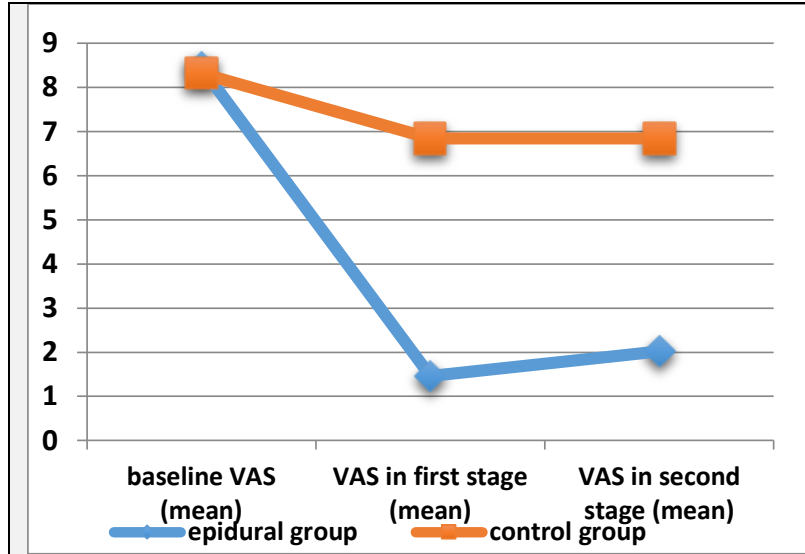

Graph 2. Comparison of Visual Analogue Scale, Gestational Age between Epidural Group and Control Group at Various Stage of Labour

\section{DISCUSSION}

Normal labour and birth, although viewed as a normal physiological process, can produce significant pain, requiring appropriate pain management. A variety of anaesthesia methods for delivery are used in different regions of the world. Most widely used method to reduce labour pain was epidural anaesthesia. In the developed countries more than
$60 \%$ hospitalised women used epidural analgesics for relief of labour pain. This indicates that the method is reliable and preferred method of anaesthesia. ${ }^{8}$ The main objective of an epidural anaesthesia is to make a woman more comfortable during labour. The term 'epidural' refers to "the space of spine where local anaesthetic is delivered. It is a local anaesthetic. The use of this technique allows the patient to be fully awake and participating in all aspects of the birthing process". Epidural anaesthesia along with an experienced anaesthetist, a dedicated obstetrician and a trained midwife has capability to transform the painful and stressful labour event into a less stressful event. ${ }^{5}$

Epidural analgesia is associated with prolonged labour, which in turn leads to assisted vaginal birth. ${ }^{6}$ Some factors are associated with no pain relief or block failure with epidural such as, obesity, multiparity, cervical dilation of more than $7 \mathrm{cms}$ at insertion, history of previous failure of epidural anaesthesia etc. Epidural analgesia may cause foetal bradycardia. The observations of the study are presented below.

\section{Maternal Demographic Variables}

In the present study, mean age of women in epidural group was 23.18 year with standard deviation of 3.75 while mean age of women in epidural group was 23.80 year with standard deviation of 3.89. There was no statistical difference between the mean age of both the study groups ( $p>0.05)$. In a study done by Agrawal D et al. ${ }^{9}$, mean age of the patients in epidural group was 28.1 years and in cases who didn't receive epidural anaesthesia is 26.9 years. Mean age in my study is much lower than the study done by Agrawal D et al. Mean age in my study is much lower than the study done by Agrawal D et al. In the present study, highest women were in 50-60 kg weight category in both, epidural group (60\%) and cases who didn't receive epidural anaesthesia (55.8\%). Mean weight of women in epidural group was $56.06 \mathrm{~kg}$ with standard deviation of 5.26 while mean weight of women in cases who didn't receive epidural anaesthesia was $57.65 \mathrm{~kg}$ with standard deviation of 4.98. There was no statistical difference between the mean weight of both the study groups ( $p>0.05$ ). In a study done by Agrawal D et al, mean weight of the patients in epidural group was $65.06 \pm 4.84 \mathrm{~kg}$ and in cases who didn't receive epidural anaesthesia it was $64.65 \pm$ $5.46 \mathrm{~kg}$. Mean weight in the present study was much lower than the study done by Agrawal D et al.

In the present study, highest women were in 150-155 cm height category in both, epidural group (45\%) and control group (42.5\%). Mean height of women in epidural group was $152.1 \mathrm{~cm}$ with standard deviation of 6.22 while mean height of women in control group was $151.3 \mathrm{~cm}$ with standard deviation of 7.03. There was no statistical difference between the mean height of both the study groups ( $p>0.05)$. In a study done by Agrawal D et al. , mean height of the patients in epidural group was $163.1 \pm 8.31 \mathrm{~cm}$ and in control group $162.4 \pm 8.33 \mathrm{~cm}$. Mean height in the present study was much lower than the study done by Agrawal D et al. In the present study, highest women were in less than 37 weeks of pregnancy in both, epidural group (65\%) and control group (70\%). Mean gestational age of women in epidural group was 37.76 weeks with standard deviation of 1.11 while mean gestational age of women in control group was 37.81 week with standard deviation of 0.98 . There was no statistical 
difference between the mean gestational age of both the study groups $(p>0.05)$. In a study done by Agrawal D et al, mean gestational age of the patients in epidural group was $37.76 \pm 1.24$ weeks and in control group $38.10 \pm 1.24$ weeks. Mean gestational age in the present study was comparable to the study done by Agrawal D et al. ${ }^{9}$

\section{Maternal Outcome of Epidural Anaesthesia First Stage of Labour}

In the present study, the average time of first stage of labour in epidural group was 6.76 hours with standard deviation of 1.96 while mean duration of first stage of labour in control group was 7.16 hours with standard deviation of 1.82 . There was no statistical difference between the mean duration of first stage of labour in both the study groups ( $p>0.05$ ). In a study done by Agrawal D et al, mean duration of first stage of labour was less in epidural group, i.e. $4.83 \pm 1.59$ hours, compared to the non-epidural group in which the mean duration was $5.48 \pm 1.56$ hours. Mean duration of first stage of labour in the present study was higher to the study done by Agrawal $\mathrm{D}$ et al. In a study done by Sawant $\mathrm{V}$ et $\mathrm{al},{ }^{10}$ average length of first stage of labour in the study group (epidural group) was 381.16 minutes with standard deviation of 61.75 minutes and in control group (nonepidural group) the mean duration was 370.03 minutes with standard deviation of 79.33 minutes. Mean length of first stage of labour in epidural group was higher in their study.

\section{Second Stage of Labour}

In the present study, average time of second stage of labour was 46.04 minutes with standard deviation of $13.28 \mathrm{~min}$ in study (epidural) group while average time of second stage of labour was $42.93 \mathrm{~min}$ with standard deviation of $12.10 \mathrm{~min}$ in women who didn't control group. There was no statistical difference between the mean duration of second stage of labour in both the study groups ( $p>0.05)$. In a study done by Agrawal D et al, mean duration of second stage of labour in women who received epidural anaesthesia was $33.13 \pm 12.78$ minutes and in cases who didn't receive epidural anaesthesia it was $27.53 \pm 11.73$ minutes ( $p$ 0.0137) Mean duration of second stage of labour in the present study was lower to the study done by Agrawal D et al. In a study done by Sawant V et al, mean duration of second stage of labour in women who received epidural anaesthesia was $71.63 \pm 10.11$ minutes and in cases who didn't receive epidural anaesthesia was $23.0 \pm$ 10.30 minutes. Mean duration of second stage of labour in women who received epidural anaesthesia was much higher in their study. ( $p<0.01)$. This finding differs from the present study.

\section{Mode of Delivery}

In the present study, in women who received epidural anaesthesia $57(71.3 \%)$ were normal vaginal delivery while in cases who didn't receive epidural anaesthesia 63 (78.8\%) were normal vaginal delivery. Instrumental deliveries were $8.8 \%$ and $6.3 \%$ in women who received epidural anaesthesia and in cases who didn't receive epidural anaesthesia respectively. Caesarean sections were $20.0 \%$ and $15.0 \%$ in women who received epidural anaesthesia and in cases who didn't receive epidural anaesthesia respectively. There was no statistical difference between the mode of delivery in both the study groups ( $p>0.05$ ). In a study done by Agrawal $D$ et al, in women who received epidural anaesthesia 44 (73.3\%)were normal vaginal delivery while in cases who didn't receive epidural anaesthesia $52(86.67 \%)$ were normal vaginal delivery. Instrumental deliveries were $10(16.7 \%)$ and $4(6.67 \%)$ in women who received epidural anaesthesia and in cases who didn't receive epidural anaesthesia respectively. Caesarean sections were $6(10 \%)$ and 4 (6.67 $\%$ ) in women who received epidural anaesthesia and in cases who didn't receive epidural anaesthesia respectively. ( $\mathrm{p}>0.05$ ) In a study done by Sawant $\mathrm{V}$ et $\mathrm{al}^{10}$ in women who received epidural anaesthesia $25(83.3 \%)$ were normal vaginal delivery while in cases who didn't receive epidural anaesthesia $26(86.67 \%)$ were normal vaginal delivery. Instrumental deliveries were $3(10.0 \%)$ and $1(3.33 \%)$ in women who received epidural anaesthesia and in cases who didn't receive epidural anaesthesia respectively. Caesarean sections were $2(6.67 \%)$ and $3(10.0 \%)$ in women who received epidural anaesthesia and in cases who didn't receive epidural anaesthesia respectively. $(p>0.05)$

\section{Reasons for Instrumental Delivery}

In the present study, for instrumental delivery, foetal distress was responsible for 4 cases and prolonged second stage was in 8 cases, however there was no statistical difference in indication of instrumental delivery in both the study groups $(p>0.05)$. For caesarean section, foetal distress, prolong second stage, maternal request and nonprogress in labour were the indication. Maternal requests for caesarean section were significantly higher in cases who didn't receive epidural anaesthesia compared to women who received epidural anaesthesia. $(\mathrm{p}<0.05)$ In a study done by Gawandi PS et al. ${ }^{11}$ in women who received epidural anaesthesia 43 (86\%) were normal vaginal delivery while in cases who didn't receive epidural anaesthesia $45(90.0 \%)$ were normal vaginal delivery. Instrumental deliveries were $3(6.0 \%)$ and 2 (4.0 $\%)$ in women who received epidural anaesthesia and in cases who didn't receive epidural anaesthesia respectively. Caesarean sections were $4(8.0 \%)$ and 6 (3.0 \%) in women who received epidural anaesthesia and in cases who didn't receive epidural anaesthesia respectively. ( $p>0.05)$ For instrumental delivery, foetal distress was responsible for 1 case and prolonged second stage was in 2 cases in women who received epidural anaesthesia, however there was no statistical difference in indication of instrumental delivery in both the study groups ( $p>0.05$ ). For caesarean section, foetal distress was responsible for 2 case and prolonged second stage was in 2 cases in women who received epidural anaesthesia.

\section{APGAR Score}

In a study done by Agrawal D et al, at 5 min mean APGAR score was less than 7 in $8(13.3 \%)$ and $6(10.0 \%)$ babies respectively in women who received epidural anaesthesia and cases who didn't receive epidural anaesthesia. The APGAR scores at 5 min were also statistically similar in both groups in their study ( $\mathrm{p}$-value $=0.569)$. In a study done by Gawandi PS et al. ${ }^{11}$, at 1 min mean APGAR score was less than 7 in $2(4.0 \%)$ and $1(2.0 \%)$ babies respectively in women who received epidural anaesthesia and cases who didn't receive epidural anaesthesia. However, on analysing neonatal outcome it has been seen that there is no statistically significant difference in APGAR score in both groups. At 5 min 
mean APGAR score was 7 or more in all cases both in women who received epidural anaesthesia as well as cases who didn't receive epidural anaesthesia. Our results demonstrated no significant difference in neonatal outcome (APGAR score) between epidural and cases who didn't receive epidural anaesthesia as in almost all other studies. ${ }^{12,13,14,15}$

\section{Visual Analogue Scale (VAS)}

Visual analogue scales (VAS) are psychometric response scales used to measure subjective characteristics or attitudes and have been used in the past for a multitude of disorders, as well as in market research and social science investigations, among others. VAS was first described in 1921 and referred to at the time as a "graphic rating method".

In a study done by Gawandi PS et al. , in women who received epidural anaesthesia $30(60.0 \%)$ women had excellent VAS, 19 (38.0\%) had good/satisfactory VAS, 1 (2.0\%) had inadequate VAS while failure of analgesia was not seen in any case. In the present study, before the analgesia (basal) mean VAS was 8.45 and 8.32 in women who received epidural anaesthesia and cases who didn't receive epidural anaesthesia respectively. During the first stage of labour mean VAS was significantly less in women who received epidural anaesthesia (1.46) compared to cases who didn't receive epidural anaesthesia (6.84) $(p<0.001)$. Similarly, during the second stage also the mean VAS was significantly less in women who received epidural anaesthesia (2.02) compared to cases who didn't receive epidural anaesthesia (8.00) $(\mathrm{p}<0.001)$.

In a study done by Gawandi PS et al, before the analgesia (basal) mean VAS was 8.88 in women who received epidural anaesthesia. During the first stage of labour mean VAS was significantly less in women who received epidural anaesthesia (1.70) in comparison to before analgesia VAS. Similarly, during the second stage also the mean VAS was significantly less in women who received epidural anaesthesia (2.13). In the present study, hypotension \& tachycardia was found in $2(2.5 \%)$, Urinary retention was found in $1(1.3 \%)$, Backache was found in $2(2.5 \%)$, Headache was found in 3 (3.8\%), Pyrexia was found in 2 (2.5\%), and Motor Paresis was found in 1 (1.3\%). In a study done by Gawandi PS et al, hypotension \& tachycardia, urinary retention, Backache and Motor Paresis was found in 1 (2.0\%) each. Headache and Pyrexia was not found any of the cases. Incidence of side effects was higher in my study in comparison to study done by Gawandi et al.

\section{CONCLUSIONS}

Based on the current study results and review of the similar published studies, we conclude that use of epidural anaesthesia is very effective in reducing labour pain. The currently used analgesic agents in epidural analgesia cause minimal complications. Use of epidural analgesic during the later stage of labour, when cervical dilatation was more than $4 \mathrm{cms}$, provides better analgesic effect with minimal side effect and almost equivalent duration of labour. Similar labour duration indicates minimal motor blockage of epidural analgesic which enables women to actively participate in foetus expulsion. Epidural analgesia doesn't unnecessarily increase operative delivery rate and had no adverse effect on APGAR score of newborn. Epidural techniques are valuable as same route and drugs can be used if caesarean section is required. The analgesic effect can be maintained as long as needed and even after delivery to relieve postoperative pain.

\section{REFERENCES}

[1] Beigi NMA, Broumandfar K, Bahadoran P, et al. Women's experience of pain during childbirth. Iranian Journal of Nursing and Midwifery Research 2010;15(2):77-82.

[2] ADAPTE Collaboration. ADAPTE manual for guideline adaptation, version 1.0. Canada: Guidelines International Network. 2007.

[3] Wong CA. Epidural and spinal analgesia/anesthesia for labor and vaginal delivery. In: Chestnut's obstetric anesthesia: principles and practice. Philadelphia, PA: Mosby Elsevier 2009: p. 429-92.

[4] Labor S, Maguire S. The pain of labour. Reviews in Pain 2008;2(2):15-9.

[5] Javed L, Salick A, Farooqi NJ. Epidural analgesia in labour in relation to the rate of instrumental deliveries. Ann K E Med J 2005;11:307-10.

[6] Agaram R, Dougles MJ, McTaggart RA, et al. Inadequate pain relieve with labour epidurals. A multivariate analysis of associated factors. Int J Obstet Anesth 2009;18(1):10-4.

[7] Doughty A. Walter Stoeckel (1871-1961). A pioneer of regional analgesia in obstetrics. Anaesthesia 1990;45(6):468-71.

[8] Poole JH. Analgesia and anesthesia during labor and birth: implications for mother and foetus. J Obstet Gynecol Neonatal Nurs 2003;32(6):780-93.

[9] Agrawal D, Makhija B, Arora M, et al. The effect of epidural analgesia on labour, mode of delivery and neonatal outcome in nullipara of India, 2011-2014. Journal of Clinical and Diagnostic Research: JCDR 2014;8(10):0C03-0C06.

[10] Sawant V, Kumbhar A. Labour with low dose epidural analgesia: maternal perception and foetal outcome. Int J Reprod Contracept Obstet Gynecol 2018;7(2):689-93.

[11] Gawandi PS, Chandrakant JA. Maternal and neonatal outcome in patients with epidural analgesia with compare to patients without epidural analgesia. Research and Reviews: Journal of Dental Sciences 2014;4(2):78-85.

[12] Leighton BL, Halpern SH. The effects of epidural analgesia on labor, maternal and neonatal outcomes: a systematic review. Am J Obstet Gynecol 2002;186(5 Suppl Nature):S69-S77.

[13] Fyneface-Ogan S, Mato CN, Anya SE. Epidural anesthesia: views and outcomes of women in labour in a Nigerian hospital. Ann Afr Med 2009;8(4):250-6.

[14] Anim-Somuah M, Md. Smyth R, Jones L. Epidural versus non-epidural or no analgesia in labour. Cochrane Database of Systematic Reviews 2011;(12):CD000331.

[15] Sienko J, Czajkowski K, Swiatek-Zdzienicka M, et al. Epidural analgesia and the course of delivery in term Primiparas. Ginekol Pol 2005;76(10):806-11 